\title{
Quality technical talent development status quo and development trend analysis
}

\author{
Xiang-hong $\mathrm{HU}^{1, \mathrm{a}}$, Shan-Lin YANG ${ }^{1, \mathrm{~b}}$ Wei-Guo HOU ${ }^{2, \mathrm{c}}$ Zhang-Yong XIE ${ }^{3, \mathrm{~d}}$ \\ ${ }^{1}$ HeFei University of Technology, China \\ ${ }^{2}$ The Fifth Electronics Research Institute of Ministry of Industry and Information Technology, China \\ ahuxh@ceprei.com, ${ }^{b}$ hgdysl@gmail.com, chouweiguo@139.com, ${ }^{\mathrm{d}}$ ytmf1988@126.com
}

Keywords: China, quality, personnel training, development trend.

\begin{abstract}
Quality and efficiency has gradually become a new era, one of the key foothold to promote economic development at home and abroad. It is an important objectives and strategic initiatives to improve the quality and efficiency of China's economic advance along the road of scientific development, and it fundamental lies in the construction of the training of personnel. This article from the quality of talent-building situation, analyzes its structure distribution characteristics, and the existing building mode, for which the drawbacks and shortcomings, and compares the existing experience of other countries, the construction of which the quality of the manufacturing industry personnel efficiency evaluation model to fix personnel development investment the generated ratio, and adjust the personnel composition ratio according to the model analysis results..
\end{abstract}

\section{Introduction}

The quality system has become an important foundation for support of economic development in the new period. The domestic quality personnel development and training has become increasingly important, but there are still many problems.

Quality practitioners are engaged in quality management, audit, inspection of the quality of engineering and technical personnel, as well as in the detection, measurement and standardization of professional and technical personnel.

\section{Construction Status and Problems of Quality Skilled Personnel at Home and Abroad}

1) Staus

China since the 1978 implementation of total quality management (TQM) education, from the seven tools of propaganda and popularization of QC group activities to a series of quality management and quality assurance standards publicizing and enterprise quality system certification, China's quality vocational training and education has not stopped and has made great achievements, has trained a batch of quality workers for our industry. Central leadership's emphasis on quality, the masses' craving for high-quality products, put the quality work forward higher requirements, quality cannot be separated from the quality of high-quality talent. The CPC Central Committee and the State Council have always attached great importance to the quality work. November 11, 2008, President Hu Jintao made important instructions: Quality is the life. Financial crisis put forward higher requirements to the quality of qualified personnel, but also increased the difficulty of inputs. The one hand, the financial crisis made higher pressure faced by the majority of enterprises to enhance the level of quality, promote structural adjustment, and the increasingly high demand for quality talent. On the other hand, the financial crisis caused lesser external demand. China's economic development suffers from the continuing impact of the many uncertainties of the international and domestic, and faces unprecedented challenges.

The United States is the birthplace of statistical quality control and modern quality management thinking. In the 1920s, Bell Labs, Dr. Shewhart (WG Shewhart) promoted Shewhart control charts. In the 1930s, quality management experts Feigenbaum (AV Dr. Feigenbaum) and Juran (JM Juran) 
proposed the new concept of total quality management In the 1980s,Motorola successfully implemented Six Sigma strategy, the quality of engineering education and research in the United States in the research team to study the depth and research are the world's second to none. Britain, France, Germany and other European countries, in the 1990s, has set up a quality Master of Engineering, doctorate, has formed a comprehensive personnel training system, and provides a solid support for quality assurance of various industries, a strong impetus to economic development.

Department of Industrial Engineering is set up in the University of the United Kingdom, Australia, Singapore and other Commonwealth countries, and thus the quality of engineering education and research is a manufacturing-related engineering faculties, such as the University of Wollongong, Australia, only in the Department of Mechanical Engineering, "manufacturing and service industries, statistical process control, industrial quality management, "industrial quality technology", "quality improvement system," "the quality of the engineering design "," international quality " were founded for undergraduate and postgraduate. In Switzerland, known for its high-quality precision manufacturing, quality engineering education in higher education is also very important.

2) Problems

The overall quality level of Chinese-made products is also rising, the emergence of a group of well-known brands such as Haier, Lenovo, Huawei, Media.However, due to the late start, coupled with the development of quality professional academic education in China is slow, and there are still some problems in the overall level of quality talent in China and team building. Comparing with the international developed countries, there is still a gap, mainly reflected in the following aspects:

The quality insufficient number of personnel, job demand gap

The survey showed that the quality total number of employees in China accounted for the total number of enterprise workers an average of $6.08 \%$. Requirements in accordance with the National Defense Science and Industry Bureau of the quality of military enterprises, quality staff ratio requirement is $8-12 \%$, in developed countries this ratio is higher. Whether the existing level compared to foreign or domestic requirements, it is clearly insufficient. Such as textiles, machinery, electronics, automotive, and other industries related to people's livelihood, quality employees accounted for the proportion of the number of enterprises is generally low. If The quality of these basic manufacturing industry are not fully protected, in the follow-up of industrial production process, it is difficult to produce good productivity, and it has played a significant role in the constraints for raising the level of industrial production in China, also the sound development of the economy. Especially after China's accession to the WTO, the industrial production has entered the orbit of the international, competitors of the industry production Europe and the United States, Japan and other developed countries with the quality assurance system. In the number of exposed "Made in China" quality events, Quality has been the subject of criticism.

\begin{tabular}{ccc} 
& \multicolumn{2}{c}{ Tab 1 Quality employees accounted for the proportion of the total number of enterprises } \\
\hline No. & Industry & Quality employees accounted for the proportion of the total number of enterprises \\
$\mathbf{1}$ & Light Industry & $10.75 \%$ \\
$\mathbf{2}$ & Building Materials & $9.61 \%$ \\
$\mathbf{3}$ & Non-ferrous metals & $8.77 \%$ \\
$\mathbf{4}$ & Shipping & $8.37 \%$ \\
$\mathbf{5}$ & Petrifaction & $7.71 \%$ \\
$\mathbf{6}$ & Car & $7.59 \%$ \\
$\mathbf{7}$ & Scorch & $6.16 \%$ \\
$\mathbf{8}$ & Electronic information & $5.06 \%$ \\
$\mathbf{9}$ & Iron and steel & $3.63 \%$ \\
$\mathbf{1 0}$ & Machinery & $3.08 \%$ \\
$\mathbf{1 1}$ & Other & $2.65 \%$ \\
$\mathbf{1 2}$ & Spinning & $2.04 \%$ \\
\hline
\end{tabular}




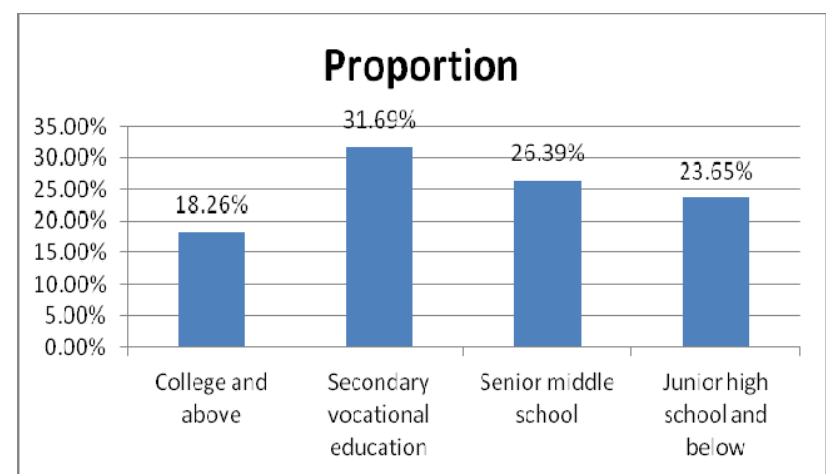

Fig 1 the level of quality of domestic personnel qualifications questionnaire

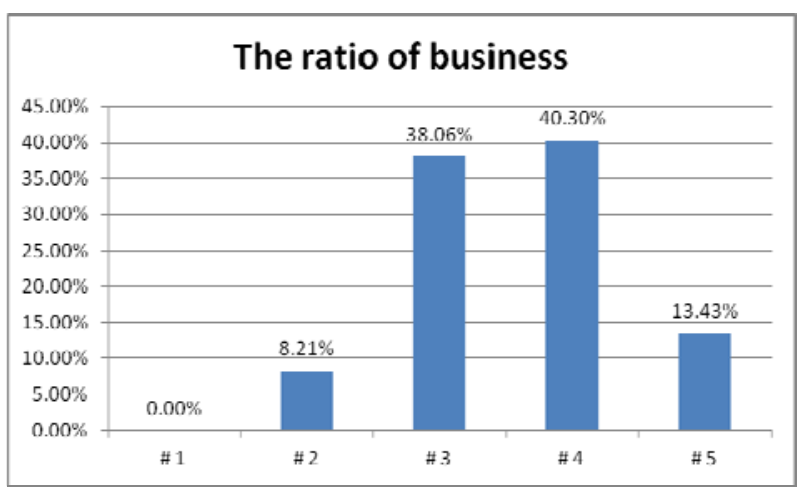

Fig 2 Quality practitioners revenue qualifying

In addition, the quality of domestic personnel from Table 1 on the practitioner level, quality of skills generally has been on low level. There are many reasons, the main reason is the domestic later quality attention than foreign country, the training of professionals did not form a complete system, many quality personnel education and training is in the dark ahead, the quality of education in a professional form college training quality personnel is not sufficient. Mostly military-related colleges and universities open such a professional; and the degree of attention for the quality of talent is not as the foreign. This is especially true in the quality of employees the level of wages and jobs extent.

Perfect quality management and evaluation system has been created in the developed Western countries, mainly the United States and Japan, and also have the qualification certification system. Quality employees have become the core of the corporate sector employees. Quality personnel in a qualified, obtain the appropriate qualifications, the corresponding increase of wages will also help encourage quality continuously improve their own skill level.

At the national level, the quality of job functions of employees divided into the following categories: quality management, quality audit, quality inspection technology, reliability, management, software quality management, testing, measurement and standardization of 8 professional categories. Quality audit, quality detection technology, testing personnel accounted for the overall quality of employees in the proportion of the vast majority. Among these positions, the requirements of the quality of personnel will be lower compared with quality management, software quality management personnel, and most companies often supply insufficient investment in a relatively require a higher quality posts.

In most of the production process, in order to ensure the quality of their products and their competitiveness, there will be the person who set up the posts. But investment on this part is difficult to quickly generate the income effect in the short term. Benefits in the quality of work for an enterprise will bring the good reputation of the brand, which requires a long process of establishing. The moment part of domestic enterprises often does not attach importance to this process due to the shortsightedness. Moreover, it is difficult to carry out quantitative scale for the slow-effective quality work, thus increasing the difficulty of the evaluation of the effectiveness, and it has seriously affected the business managers for the attention of quality.

\section{Strategies and Measures}

Quality work should ultimately rely on people to implement. From R \& D, design, manufacturing, testing, distribution until all aspects of details need a variety of management, technology, skilled personnel at various levels to implement checks at each level. It can be said that the quality of high-quality personnel is to enhance the quality of basic security.

1) The importance of advocacy work for the state, enterprises to strengthen quality

With the other ministries of the national union, vigorously promote the good deeds of the preferred quality talent and quality employees, through television, radio, newspapers, Internet and other media to create a glorious quality talent, a great social atmosphere of quality practitioners and form the consciousness of universal attention to quality. Only in this way the quality of the work may effectively carried out. 
2) Improve the industrial quality and skilled personnel education and training system

A leader in education and training demonstration bases should be established. quality and skilled personnel education and training system With universities, associations, enterprises, technical schools, vocational schools, and various types of vocational training institutions main supplemented to public vocational skills education and training institutions and private vocational skills education and training institutions should be established.

3) Unified management for quality talent, expert information, and construction of the database

To establish quality practitioners and the quality of expert database governed directly by the Ministry of Industry and Information Technology. It will he to understand the basic situation of the country's industrial enterprises quality practitioners and quality experts, demand and changes in real-time.

4) The development of quality education of employees training system

Carry out the quality education of employees in the top-level design of the training system, supply the quality of knowledge and technology outline of the system for improving the quality of employees and related engineering and technical personnel theoretical level and practical ability.

5) Across all sectors, the quality of talent-owned certification

Research shows that quality personnel qualification played a very important role in the quality, it can help both the quality of talent continue to get new skills and knowledge to enhance their professional competence, but also for the quality to bring more competitive compensation, which can form a benign promotion mechanism conducive to the development of qualified personnel.

\section{Summary}

In the new period of development of a diversified economy, innovation is the driving force for development, and quality is the fundamental guarantee for the development. Quality talent team construction in China started late, but it got more and more attention. How to build a strong quality assurance system is a very difficult task, but also the task which must be completed. This paper presents the problems existing in, on the quality of personnel training built to take advantage of a variety of strategies and measures. Only by raising the attention of quality (including quality talent), continuing to learn the advanced experience of foreign countries, exploring their new theories, new methods will be effective to build our quality personnel system and provide protection for the quality system of the entire country.

\section{References}

[1]. Wen Shiyan, "Evaluating the quality of higher vocational talent trained by learning and working (Published Conference Proceedings style),” Artificial Intelligence and Education (ICAIE), 2010 International Conference, pp. 9- 12.

[2]. Xiao Qimin, Wang Huajun. "Study on quality training of senior engineering talents for engineering practices(Published Conference Proceedings style)," Computer Science \& Education (ICCSE), 2012 7th International Conference, pp. 1621- 1624.

[3]. Xiaoming Bi, Na Xu. "Core competitiveness-based high-quality applied network talents training model (Published Conference Proceedings style),” Educational and Information Technology (ICEIT), 2010 International Conference on, V3, pp. 537-540.

[4]. Wei Peng. "The personnel training and quality education of college interior design profession(Published Conference Proceedings style)," Computer-Aided Industrial Design \& Conceptual Design (CAIDCD), 2010 IEEE 11th International Conference on, pp. 9-12.

[5]. Zhang Shibin. "Innovation on integration reforms of education \& teaching to improve quality of personnel training(Published Conference Proceedings style)," Consumer Electronics, Communications and Networks (CECNet), 2011 International Conference on, pp. 3222-3225. 